\title{
Comparison of single-dose and extended-dose antimicrobial prophylaxis for preventing surgical site infections after curative surgery for gastric adenocarcinoma
}

\author{
Ümit Mercan*, Ogün Erşen, Ali Ekrem Ünal
}

Surgical Oncology, General Surgery Department, Faculty of Medicine, Ankara University, Ankara, Turkey.
*Correspondence to : Ümit Mercan (umit.mercan@yahoo.com.tr )
(Submitted: 03 March 2020 - Revised version received:24 March 2020 - Accepted: 10 April 2020 - Published online: 26 June 2020)

\begin{abstract}
Objectives There is no consensus on the duration of antimicrobial prophylaxis (AMP) for prevention of surgical site infections (SSI) after curative gastrectomy for gastric adenocarcinoma and the data are limited. In this study, we aimed to compare the effect of single-dose and extended-dose AMP on SSI prevention.

Methods A total of 210 patients who underwent curative gastrectomy for gastric cancer included in the study. Patients who received a single dose of $1 \mathrm{~g}$ cefazolin 30 min before the surgical incision were determined as single-dose group and the patients who received $1 \mathrm{~g}$ cefazolin one time $30 \mathrm{~min}$ before the surgical incision and every $12 \mathrm{~h}$ until the first postoperative day were determined as extended-dose group. Demographic characteristics, postoperative outcomes, and the types and incidence of SSI were compared in two groups and risk factors for SSI development were analyzed.

Results There was no significant difference in the demographic characteristics and postoperative outcomes in both AMP groups in the general patient population and in the subgroups formed based on different clinicopathological and operative factors. There was no significant difference in the incidence of SSI between the two groups (23,4\% and $26,7 \% p=0,346)$. Age, diabetes mellitus, chronic obstructive pulmonary disease, operation time, and operative approach were found to be independent risk factors for SSI development. Conclusion In patients undergoing curative gastrectomy for gastric adenocarcinoma, it has been found that the use of extended-dose AMP has no effect on reducing the incidence of SSI and single-dose AMP is sufficient and safe.

Keywords Antibiotic prophylaxis, Stomach neoplasms, Surgical wound infection
\end{abstract}

\section{Introduction}

Surgical site infections (SSIs) remain one of the most confounding issues of the surgeons, despite the numerous revolutions in the field of surgical technique, asepsis and antisepsis in the historical process and current technologies. ${ }^{1}$ Although the development of effective antibiotics which are easily applied in clinical practice with the concept of antimicrobial prophylaxis (AMP), the incidence of SSI is reported to reach $20 \%$ depending on many patients and disease-related factors. ${ }^{2}$ This situation is no different for stomach cancer surgery, which is one of the most major intaabdominal surgeries, and the incidence of SSI was found to be between $5 \%$ and $20 \% .^{3}$

AMP is widely applied before many surgical procedures, and studies have shown that it effectively prevents SSI depending on the distribution of patients, the effectiveness of the antibiotic used, and the surgical procedure performed. ${ }^{4,5}$ Although it has been clarified which antibiotic will be used in which surgical procedure and the effective doses of the antibiotics used, the evidence on the duration of AMP is limited. Although it has been concluded that single dose AMP is sufficient in colorectal and hepatobiliary surgery, a clear consensus has not been achieved, except for a few randomized studies that advocate the same idea with limited evidence in gastric cancer surgery. ${ }^{6-10}$

While single-dose AMP prior to gastric cancer surgery was the common concept in the West, it was shown in a survey on surgeons in the Far East that more than $60 \%$ of surgeons continued prophylaxis in the postoperative period. ${ }^{11}$ Based on the limited number of studies and clinical experience, there are no clear data on the duration of antibiotic use, although the single-dose AMP is considered to be more advantageous than the extended-dose AMP because of the potential complications of extended-dose AMP such as drug side effects and bacterial resistance development. Therefore, in this study, we aimed to compare the effectiveness of single-dose and extended-dose AMP in preventing the development of SSIs in patients undergoing curative gastrectomy with the diagnosis of gastric cancer.

\section{Material and Methods}

\section{Patient Selection and Data Collection}

A total of 210 patients who underwent curative gastrectomy for gastric cancer between January 2015 and January 2019 were included in the study. Patients whose results could not be reached, who underwent palliative procedures, who had metastatic disease at the time of diagnosis, who underwent emergency surgery due to bleeding or perforation, who received neoadjuvant chemotherapy, who received antibiotic treatment preoperatively for various reasons, and who had any immune system disease were excluded from the study. Demographic informations, operational results, and pathology reports of patients were analyzed retrospectively using the hospital database. Prophylactic antibiotic regimens applied by different surgical teams in our clinic were screened retrospectively via electronic file system. Patients who received a single dose of $1 \mathrm{~g}$ cefazolin $30 \mathrm{~min}$ before the surgical incision were determined as the first group (single-dose AMP) and who received $1 \mathrm{~g}$ cefazolin one time $30 \mathrm{~min}$ before the surgical incision and every $12 \mathrm{~h}$ until the first postoperative day were determined as the second group (extended-dose AMP).

Pathological stages were determined according to the Tumor Node Metastasis (TNM) classification of the 7th edition of the International Cancer Control. ${ }^{12}$ Deaths occurred 
within 30 days postoperatively has been determided as in-hospital mortality. Complications related to the surgical site were accepted as local complications and the others as systemic complications. The type and severity of postoperative complications were graded and categorized based on the Modified Clavien Dindo Classification. ${ }^{13}$ Infections developed within 30 days postoperatively were evaluated as SSI and were determined based on National Nosocomial Infections Surveillance system data. ${ }^{2}$ SSIs were categorized as superficial incisional, deep incisional, and organ/space infections. Demographic characteristics, postoperative results, and surgical site infections were compared between two groups.

This study was approved by the Ethics Committee.

\section{Operation and Perioperative Care}

All operations in our clinic were performed in strict accordance with the rules of routine asepsis and antisepsis. Preoperative mechanical bowel cleansing was performed. Preoperative fasting was achieved for $8 \mathrm{~h}$. Intraoperative normothermia was provided by the anesthesia team. Laparoscopic gastrectomy was performed in patients with early stage disease and technically appropriate. Laparotomy was performed in patients with locally advanced disease and not eligible for laparoscopic surgery. Two of $10 \mathrm{~mm}$ and three of $5 \mathrm{~mm}$ ports were used in patients undergoing laparoscopic surgery. After dissection, the specimens were removed by expanding the umbilical camera port via a spesimen bag. A standard midline incision extending from the xiphoid bone to the umbilicus was performed in laparotomies. Depending on the tumor locations and clinical conditions, patients underwent appropriate lymph node dissection with distal or total gastrectomy. Silk and polyglactin suture materials were used in the abdomen. The intraabdominal and subcutaneous cavities were washed with sterile saline solutions before closing. While surgical incisions were closing, double-layer polydioxanon (PDS) was used in the abdominal fascia and polypropylene suture was used in the skin. Two Jackson pratt drains and nasogastric tubes were placed in each patient. After anastomotic leakage control using oral methylene blue on the third postoperative day, the nasogastric tubes of the patients were withdrawn and the patients have started oral feeding. Patients who had adequate oral intake and who had not required inpatient treatment were discharged with the suggestion of outpatient control.

\section{Statistical Analysis}

Data were presented as numbers with mean \pm standard deviation or percentage. The suitability of data for normal distribution was determined by Kolmogorov-Smirnov test and histogram graphs. Student's $t$-test, Mann-Whitney $U$ test, $\chi 2$ test, or Fisher's exact test were used for comparisons between numerical or categorical data. The binary logistic regression model was used to analyze the risk factors for surgical site infections. All statistical analyzes were performed using IBM SPSS Statistics 23. For all tests, values less than $p<0.05$ were significant.

\section{Results}

Of the 210 patients included in the study group, $152(72,4 \%)$ were male and the mean age was $60.89 \pm 8.56$ years. There were 124 (59\%) patients in the single-dose group and $86(41 \%)$ patients in the extended-dose group. The demographic characteristics of the groups are summarized in Table 1. There was

Table 1. Comparison of patient characteristics between two groups.

\begin{tabular}{|c|c|c|c|c|}
\hline \multirow[b]{2}{*}{ Variables } & \multirow[b]{2}{*}{$\begin{array}{l}\text { Total } \\
(n=210)\end{array}$} & \multicolumn{2}{|c|}{ Duration of AMP } & \multirow[b]{2}{*}{$p$ value } \\
\hline & & $\begin{array}{l}\text { Single-dose group } \\
(n=124)\end{array}$ & $\begin{array}{l}\text { Extended-dose group } \\
(n=86)\end{array}$ & \\
\hline Age & $60,89 \pm 8,56$ & $60.71 \pm 8.42$ & $61,14 \pm 8.8$ & 0,722 \\
\hline Gender (male) & $152(72,4)$ & $90(72,6)$ & $62(72,1)$ & 0,530 \\
\hline BMI $\left(\mathrm{kg} / \mathrm{m}^{2}\right)$ & $21,14 \pm 3,24$ & $21 \pm 3.09$ & $21.21 \pm 3.45$ & 0,686 \\
\hline $\begin{array}{c}\text { TNM Stage }^{*} \\
\text { Stage } 1 \\
\text { Stage } 2 \\
\text { Stage } 3\end{array}$ & $\begin{array}{l}38(18,1) \\
67(31,9) \\
105(50)\end{array}$ & $\begin{array}{l}23(18,5) \\
31(25) \\
70(56,5)\end{array}$ & $\begin{array}{l}15(17,4) \\
36(41,9) \\
35(40,7)\end{array}$ & 0,029 \\
\hline $\begin{array}{l}\text { Smoking } \\
\text { Comorbid Diseases } \\
\text { Diabetes Mellitus } \\
\text { Hypertension } \\
\text { COPD }\end{array}$ & $\begin{array}{l}69(32,9) \\
40(19) \\
100(47,6) \\
28(13,3)\end{array}$ & $\begin{array}{l}44(35,5) \\
25(20,2) \\
60(48,4) \\
17(13,7)\end{array}$ & $\begin{array}{l}25(29,1) \\
15(17,4) \\
40(46,5) \\
11(12,8)\end{array}$ & $\begin{array}{l}0,379 \\
0,450 \\
0,509\end{array}$ \\
\hline $\begin{array}{l}\text { Operative Approach } \\
\text { Laparotomy } \\
\text { Laparoscopy }\end{array}$ & $\begin{array}{l}100(47,6) \\
110(52,4)\end{array}$ & $\begin{array}{l}62(50) \\
62(50)\end{array}$ & $\begin{array}{l}38(44,2) \\
48(55,8)\end{array}$ & 0,246 \\
\hline $\begin{array}{l}\text { LND } \\
\text { D1/D1+ } \\
\text { D2/D2+ }\end{array}$ & $\begin{array}{l}38(18,1) \\
172(81,9)\end{array}$ & $\begin{array}{l}23(18,5) \\
101(81,5)\end{array}$ & $\begin{array}{l}15(17,4) \\
71(82,6)\end{array}$ & 0,494 \\
\hline $\begin{array}{l}\text { Gastric Resection } \\
\text { DG } \\
\text { TG }\end{array}$ & $\begin{array}{l}91(43,3) \\
119(56,7)\end{array}$ & $\begin{array}{l}50(40,3) \\
74(59,7)\end{array}$ & $\begin{array}{l}41(47,7) \\
45(52,3)\end{array}$ & 0,180 \\
\hline
\end{tabular}

Values are presented as mean \pm standard deviation or number (\%). AMP: Antimicrobial Prophylaxis, BMI: Body Mass Index, TNM: Tumor Node Metastasis, COPD: Chronic Obstructive Pulmonary Disease, LND: Lymph Node Dissection, DG: Distal Gastrectomy, TG: Total Gastrectomy. ${ }^{*}$ TNM stage was based on the 7th edition of the American Joint Committee on Cancer staging system. ${ }^{2}$ 
no significant difference between two groups in terms of age, gender, BMI, comorbid diseases, smoking, operative approach, type of operation, and lymph node dissection. The single-dose group had significantly more TNM stage 3 patients than the extended-dose group $(p=0,029)$.

The comparison of postoperative outcomes between the two groups are summarized in Table 2 . The mean length of hospital stay was $8.58 \pm 4.06$ days and there were $9(4,3 \%)$ patients who developed mortality within 30 days. SSI developed in $52(24,8 \%)$ patients, of which $23(11 \%)$ had wound infection, 12 (5,7\%) had intraabdominal abscess, $15(7,1 \%)$ had anastomosis leakage, and $9(4,3 \%)$ due to pancreatic fistula. There was no significant difference between the groups in the incidence of SSI $(23,4 \%$ and $26,7 \%, p=0,346)$. When SSI were categorized according to their types, superficial incisional, deep incisional, and organ/space infections were observed in $5,2 \%, 3,8 \%$, and $15,7 \%$, respectively. There was no significant difference between the groups in terms of length of hospital stay, mortality rates, postoperative complication severity, SSIs, and SSI types.

The relation between the incidence of SSI and AMP duration in subgroups have been determined according to different clinicopathological and operative factors are summarized in Table 3. The incidence of SSI did not differ significantly between the single and extended-dose group in the subgroups formed by age, gender, BMI, duration and type of operation, operative approach, lymph node dissection, or TNM stage.

Risk factors for SSI determined by univariate and multivariate analyzes in total patient population are summarized in Table 4. In univariate analysis, age, BMI, smoking, diabetes mellitus, chronic obstructive pulmonary disease (COPD), operative approach, operation time, gastric resection, TNM stage, lymph node dissection, and AMP administration time were compared with SSI incidence. Age over 65, BMI over $25 \mathrm{~kg} / \mathrm{m}^{2}$, long operation time (>180 min), diabetes mellitus and COPD, operative approach and gastric resection were statistically significant among these factors. In multivariate analysis of these factors, age over 65 (OR: 2,36. 95\% CI: 0,74 4,02. $p=0,014)$ ), long operation time (OR: 2,56. 95\% CI: $1,12 \sim 4,48$. $p=0,001>$ ), presence of diabetes mellitus (OR: 5,81. 95\% CI: 2,64 8,28. $p=0,003$ ) presence of COPD (OR: 3,43. 95\% CI: $1,20 \sim 6,37 . p=0,007$ ) and laparotomy (OR: 8,45. 95\% CI: 4,48 $\sim 16,24 . p=0,001>$ ) have been found independent risk factors for the development of SSI after curative gastrectomy for gastric cancer. There was no statistically significant relationship between the duration of AMP and the development of SSI (OR 1,19. $95 \%$ CI: $0,63 \sim 2,25$. $p=0,349$ ).

\section{Discusion}

Gastric cancer surgery is one of the major intra-abdominal surgeries, and despite developing surgical methods and experience gained, wound and wound-related infectious complications still remain one of the biggest problems facing surgeons. ${ }^{1}$ Studies have shown that the incidence of SSI reaches $20 \%$ despite absolute compliance with asepsis and antisepsis rules. ${ }^{3}$ In addition to the factors associated with the surgeon and surgical procedures, it is known that many factors related to the patient and the disease play a role in the development of SSI.

Since the introduction of the concept of AMP into clinical practice, there has been a significant decrease in the incidence of SSI that has developed after many surgical procedures. ${ }^{4}$ With the introduction of more effective antibiotics, the never-ending war between surgeons and microbial agents begins to turn in favor of surgeons and clinicians, but the incidence of SSI still remains high, suggesting that information on this issue is still insufficient. While there is almost a consensus on which antibiotic to be used in which dose and in which surgical procedure, the evidence for AMP duration is insufficient and there are different practices in different clinics.

There are many clinical studies evaluating AMP duration in gastrointestinal malignancies. ${ }^{11,14-17}$ Although the efficacy of single-dose AMP has been accepted with limited evidence in colorectal and hepatobiliary surgery, most studies also included liver and pancreatic cancer patients, whose postoperative outcomes were more complex than gastric cancer,

Table 2. Comparison of postoperative outcomes between two groups.

\begin{tabular}{|c|c|c|c|c|}
\hline \multirow[b]{2}{*}{ Variables } & \multirow[b]{2}{*}{$\begin{array}{l}\text { Total } \\
(n=210)\end{array}$} & \multicolumn{2}{|c|}{ Duration of AMP } & \multirow[b]{2}{*}{$p$-value } \\
\hline & & $\begin{array}{l}\text { Single-dose group } \\
(n=124)\end{array}$ & $\begin{array}{l}\text { Extended-dose group } \\
(\mathrm{n}=86)\end{array}$ & \\
\hline $\begin{array}{l}\text { Operating Time } \\
\text { Hospital stay } \\
\text { Mortality }\end{array}$ & $\begin{array}{l}161,46 \pm 21,64 \\
8,58 \pm 4,06 \\
9(4,3)\end{array}$ & $\begin{array}{l}160,24 \pm 22 \\
8,48 \pm 4,07 \\
6(4,8)\end{array}$ & $\begin{array}{l}163,22 \pm 20,9 \\
8,71 \pm 4,06 \\
3(3,5)\end{array}$ & $\begin{array}{l}0,328 \\
0,786 \\
0,457\end{array}$ \\
\hline $\begin{array}{l}\text { Clavien-Dindo Classification } \\
\text { Grade } 3 \text { and above complications }\end{array}$ & $24(11,4)$ & $13(10,5)$ & $11(12,8)$ & 0,380 \\
\hline $\begin{array}{l}\text { SSI } \\
\text { Wound Infection } \\
\text { Inra-abdominal } \\
\text { Abscess } \\
\text { Anastomotic } \\
\text { Leakage } \\
\text { Pancreatic Fistula }\end{array}$ & $\begin{array}{l}52(24,8) \\
23(11) \\
12(5,7) \\
15(7,1) \\
9(4,3)\end{array}$ & $\begin{array}{l}29(23,4) \\
15(12,1) \\
7(5,6) \\
9(7,3) \\
4(3,2)\end{array}$ & $\begin{array}{l}23(26,7) \\
8(9,3) \\
5(5,8) \\
6(7) \\
5(5,8)\end{array}$ & $\begin{array}{l}0,346 \\
0,344 \\
0,592 \\
0,582 \\
0,283\end{array}$ \\
\hline $\begin{array}{l}\text { SSI types } \\
\text { Superficial } \\
\text { İncisional } \\
\text { Deep Incisional } \\
\text { Organ/Space }\end{array}$ & $\begin{array}{l}11(5,2) \\
8(3,8) \\
33(15,7)\end{array}$ & $\begin{array}{l}7(5,6) \\
5(4) \\
17(13,7)\end{array}$ & $\begin{array}{l}4(4,7) \\
3(3,5) \\
16(18,6)\end{array}$ & 0,805 \\
\hline
\end{tabular}

Values are presented as mean \pm standard deviation or number (\%). AMP: Antimicrobial Prophilaxis, SSI: Surgical Site Infection. 
Table 3. Relation between SSI incidance and AMP duration in subgroups.

\begin{tabular}{|c|c|c|c|c|c|}
\hline \multirow[b]{3}{*}{ Variables } & \multicolumn{4}{|c|}{ Duration of AMP } & \multirow[b]{3}{*}{$p$-value } \\
\hline & \multicolumn{2}{|c|}{ Single-dose group } & \multicolumn{2}{|c|}{ Extended-dose group } & \\
\hline & Total & SSI & Total & SSI & \\
\hline \multicolumn{6}{|l|}{ Age } \\
\hline $\begin{array}{l}<65 \\
\geq 65\end{array}$ & $\begin{array}{l}81 \\
43\end{array}$ & $\begin{array}{l}12(14,8) \\
17(39,5\end{array}$ & $\begin{array}{l}55 \\
31\end{array}$ & $\begin{array}{l}11(20) \\
12(38,7)\end{array}$ & $\begin{array}{l}0,432 \\
0,944\end{array}$ \\
\hline \multicolumn{6}{|l|}{ Gender } \\
\hline $\begin{array}{l}\text { Male } \\
\text { Female }\end{array}$ & $\begin{array}{l}90 \\
43\end{array}$ & $\begin{array}{l}21(23,3) \\
8(18,6)\end{array}$ & $\begin{array}{l}62 \\
24\end{array}$ & $\begin{array}{l}17(27,4) \\
6(25)\end{array}$ & $\begin{array}{l}0,570 \\
0,900\end{array}$ \\
\hline \multicolumn{6}{|l|}{ BMI (kg/m2) } \\
\hline $\begin{array}{l}<25 \\
\geq 25\end{array}$ & $\begin{array}{l}114 \\
10\end{array}$ & $\begin{array}{l}25(21,9) \\
4(40)\end{array}$ & $\begin{array}{l}75 \\
11\end{array}$ & $\begin{array}{l}17(22,6) \\
6(54,5)\end{array}$ & $\begin{array}{l}0,906 \\
0,529\end{array}$ \\
\hline \multicolumn{6}{|c|}{ Operating Time (min) } \\
\hline $\begin{array}{l}<180 \\
\geq 180\end{array}$ & $\begin{array}{l}102 \\
22\end{array}$ & $\begin{array}{l}10(9,8) \\
19(86,3)\end{array}$ & $\begin{array}{l}69 \\
17\end{array}$ & $\begin{array}{l}9(13) \\
14(82,3)\end{array}$ & $\begin{array}{l}0,511 \\
0,739\end{array}$ \\
\hline \multicolumn{6}{|l|}{ TNM Stage* } \\
\hline $\begin{array}{l}\text { Stage } 1 \\
\text { Stage 2-3 }\end{array}$ & $\begin{array}{l}23 \\
101\end{array}$ & $\begin{array}{l}3(13) \\
26(27,6)\end{array}$ & $\begin{array}{l}15 \\
71\end{array}$ & $\begin{array}{l}6(40) \\
17(23,9)\end{array}$ & $\begin{array}{l}0,058 \\
0,790\end{array}$ \\
\hline \multicolumn{6}{|c|}{ Operative Approach } \\
\hline $\begin{array}{l}\text { Laparotomy } \\
\text { Laparoscopy }\end{array}$ & $\begin{array}{l}62 \\
62\end{array}$ & $\begin{array}{l}21(33,8) \\
8(12,9)\end{array}$ & $\begin{array}{l}38 \\
48\end{array}$ & $\begin{array}{l}13(34,2) \\
10(20,8)\end{array}$ & $\begin{array}{l}0,973 \\
0,269\end{array}$ \\
\hline \multicolumn{6}{|l|}{ LND } \\
\hline $\begin{array}{l}\text { D1/D1+ } \\
\text { D2/D2+ }\end{array}$ & $\begin{array}{l}23 \\
101\end{array}$ & $\begin{array}{l}3(13) \\
26(25,7)\end{array}$ & $\begin{array}{l}15 \\
71\end{array}$ & $\begin{array}{l}6(40) \\
17(23,9)\end{array}$ & $\begin{array}{l}0,058 \\
0,790\end{array}$ \\
\hline \multicolumn{6}{|l|}{ Gastric Resection } \\
\hline DG & 50 & $6(12)$ & 41 & $10(24,3)$ & 0,125 \\
\hline TG & 74 & $23(31)$ & 45 & $13(28,8)$ & 0,803 \\
\hline
\end{tabular}

AMP: Antimicrobial Prophylaxis, SSI: Surgical Site Infection, BMI: Body Mass Index, LND: Lymph Node Dissection, DG: Distal Gastrectomy, TG: Total Gastrectomy. *TNM stage was based on the 7th edition of the American Joint Committee on Cancer staging system. ${ }^{12}$

making it difficult to apply study data to patients with gastric cancer. There is limited information about the duration of AMP in the prevention of SSI development only in gastric cancer patients. Although the opinion that a single dose of antibiotic use is sufficient as a result of a few randomized studies, it is seen that long-term use is a common clinical approach in studies from the Far East and there are differences in terms of study data and prophylaxis between the Eastern and Western countries. ${ }^{11,14}$ A large survey study from Japan showed that more than $60 \%$ of surgeons continue AMP after surgery. ${ }^{11}$ This may be due to heterogeneity between East and West countries in gastric cancer surgery. The large number of cases in the east causes the number of patients developing SSI to be higher and as a result, it is possible that surgeons may be directed towards more aggressive use of AMP.

Several prospective randomized studies have shown that single dose AMP is sufficient in gastric cancer surgery. In a prospective study involving 423 patients by Ohashi et al, there

Table 4. Univariate and multivariate analysis of risk factors for SSI.

\begin{tabular}{|c|c|c|c|c|}
\hline \multirow[b]{2}{*}{ Variable } & \multicolumn{2}{|c|}{ Univariate analysis } & \multicolumn{2}{|c|}{ Multivariate analysis } \\
\hline & OR (\%95 Cl) & $p$ value & Adjusted OR (\%95CI) & $p$ value \\
\hline Age $(>65)$ & $3,16(1,65 \sim 6,04)$ & 0,014 & $2,36(0,74 \sim 4,02)$ & 0,014 \\
\hline OperatingTime $(>180)$ & $4,42(2,43 \sim 8,42)$ & $0,001>$ & $2,56(1,12 \sim 4,48)$ & $0,001>$ \\
\hline Diabetes Mellitus & $4,31(2,07 \sim 8,94)$ & $0,001>$ & $5,81(2,64 \sim 8,28)$ & 0,003 \\
\hline COPD & $3,49(1,79 \sim 5,08)$ & $0,001>$ & $3,43(1,20 \sim 6,37)$ & 0,007 \\
\hline $\begin{array}{l}\text { Operating Approach } \\
\text { (laparotomy) }\end{array}$ & $6,80(3,98 \sim 17,30)$ & 0,003 & $8,45(4,48 \sim 16,24)$ & $0,001>$ \\
\hline $\mathrm{BMI}(>25)$ & $3,18(1,26 \sim 8,00)$ & 0,014 & - & - \\
\hline Gastric Resection & $2,03(1,04 \sim 3,96)$ & 0.025 & - & - \\
\hline AMP duration & - & 0,349 & - & - \\
\hline
\end{tabular}

OR: Odds Ratio, COPD: Chronic Obstructive Pulmonary Disease, BMI: Body Mass Index, AMP: Antimicrobial Prophylaxis. 
was no significant difference in the incidence of SSI between patients receiving single dose and extended dose AMP $(10,4 \%$ vs $8,1 \%$; OR 0,$764 ; 95 \%$ CI: $0,395-1,480 ; p=0,528) .{ }^{18}$ In a phase II study conducted by İmamura et al. to investigate the effectiveness of single dose prophylaxis after gastric cancer surgery, the incidence of SSI was similar in the single dose AMP group and the control group. ${ }^{19}$ In a phase III study conducted with this study and comparing single dose and extended dose AMP, it was concluded that single-dose AMP is effective and sufficient in preventing the development of SSI.$^{20}$ Similarly in our study, no significant difference was found between the two groups in terms of SSI development.

The relationship between the width of the surgical procedure and the duration of AMP is still controversial. In our study, although laparotomy and longer operation time were determined as independent risk factors on SSI development, it was found that extended dose AMP administration did not have a significant effect on the prevention of SSI development in this subgroup. These results suggest that single-dose AMP is sufficient and can be used safely in patients with more invasive procedures such as large lymph node dissection, laparotomy, long surgery time, and even multiorgan resections. It was also found in our study that extended-dose AMP use had no effect on the prevention of SSI in the entire spectrum from superficial incisional infections to deep organ infections.

Determining risk factors for SSIs is important in identifying patients at risk, taking necessary precautions and shaping the surgical approach. In our study, age, diabetes mellitus, COPD, operative approach, and operation time were determined as independent risk factors for SSI. The previously published study results by Hirao et al and Utsumi et al determining SSI risk factors appear to be consistent with our results. ${ }^{21,22}$ In order to prevent SSI development in patients with these risk factors, asepsis and antisepsis rules and intraoperative normotermi precautions should be strictly followed.

The main limitations of our study are that it has low generalization rates due to possible selection bias because of being a retrospective study conducted from a single center and it has a relatively low sample size. In addition, although the rates of surgical complications and SSI in our clinic are similar to the literature, the high rates in our study may be due to the selected sample. Our results need to be supported by randomized controlled trials with a larger patient population.

In conclusion, there is no significant difference between single-dose and extended-dose AMP in the prevention of SSI development in patients who underwent curative gastrectomy for gastric cancer. This study proves the effectiveness of single dose preoperative AMP in gastric cancer surgery. Our results support previous studies demonstrating the effectiveness of single dose prophylaxis and emphasize that the use of extended-dose AMP, which is common in Eastern countries, is not evidence-based.

\section{Acknowledgment}

I would like to thank all members of the Turkish Surgical Oncology Association supported writing of this article. Mercan U: Writing and statistical analysis Erşen O: Data collection Unal AE: Critical review

\section{Disclosure Statement}

There is no conflict of interest in writing of this article. No financial support or funding has been received.

\section{References}

1. Kolasinski W. Surgical site infections - review of current knowledge, methods of prevention. Pol Przegl Chir. 2018 Nov 6;91(4):41-47.

2. Burke JP. Infection control - a problem for patient safety. N Engl J Med 2003;348:651-656.

3. National Nosocomial Infections Surveillance System. National Nosocomial Infections Surveillance (NNIS) System Report, data summary from January 1992 through June 2004, issued October 2004. Am J Infect Control 2004:32:470-485

4. Migita K, Takayama T, Matsumoto S, Wakatsuki K, Enomoto K, Tanaka T et al. Risk factors for surgical site infections after elective gastrectomy. J Gastrointest Surg 2012;16: 1107-1115.

5. Ozalp N, Zülfikaroğlu B, Göçmen E, Acar A, Ekiz I, Koç M et al. Risk factors fo surgical site infection after gastrectomy with D2 lymphadenectomy. Surg Today 2009: 39:1013-1015

6. Gilbert DN, Moellering RC, Sande MA.. The Sanford Guide to Antimicrobial Therapy. 33rd ed. Hyde Park, VT: Antimicrobial Therapy, 2003:123-124.

7. Mangram AJ, Horan TC, Pearson ML, Silver LC, Jarvis WR. Guideline for prevention of surgical site infection, 1999. Hospital Infection Control Practices Advisory Committee. Infect Control Hosp Epidemiol 1999;20: 250-278.

8. Bratzler DW, Houck PM, Richards C, Steele L, Dellinger EP, Fry DE et al. Use of antimicrobial prophylaxis for major surgery: Baseline results from the National Surgical Infection Prevention Project. Arch Surg, 2005;140(2), 174-182

9. Kobayashi M, Takesue Y, Kitagawa Y, Kusunoki M, Sumiyama Y. Antimicrobial prophylaxis and colon preparation for colorectal surgery: Results of a questionnaire survey of 721 certified institutions in Japan. Surg Today, 2011;41(10), 1363.

10. Mohri Y, Tonouchi H, Kobayashi M, Nakai K, Kusunoki M. Mie Surgical Infection Research Group. Randomized clinical trial of single-versus multiple-dose antimicrobial prophylaxis in gastric cancer surgery. Br J Surg 2007;94:683-688.

11. Sumiyama Y, Takesue Y. Current status of prophylactic antibiotic therapy for prevention of postoperative infections after gastrointestinal surgery: A questionnaire covering 3,823 surgeons. Jpn J Chemother 2004;52: 474-485.

12. Sobin L, Gospodarowicz M, Wittekind C.. TNM classification of Malignant Tumours. 7th ed. International Union Against Cancer (UICC). New York: Wiley, 2009.

13. Dindo D, Demartines N, Clavien PA. Classification of surgical complications: A new proposal with evaluation in a cohort of 6336 patients and results of a survey. Ann Surg 2004;240:205-213.

14. Ahn HS, Yook JH, Park CH, Park YK, Yu W, Lee MS et al. General perioperative management of gastric cancer patients at high-volume centers. Gastric Cancer 2011;14:178-182

15. Dellinger EP, Gross PA, Barrett TL, Krause PJ, Martone WJ, McGowan JE Jr et al. Quality standard for antimicrobial prophylaxis in surgical procedures. Infectious Diseases Society of America. Clin Infect Dis 1994;18:422-427.

16. Takayama T, Aramaki O, Shibata T, Oka M, Itamoto T, Shimada M et al. Antimicrobial prophylaxis for 1 day versus 3 days in liver cancer surgery: A randomized controlled non-inferiority trial. Surg Today 2019;49(10), 859-869.

17. Hentzen JEKR, Smit MA, Bruins MJ, Rupert CGBM, Schreinemakers J, Ruijs GJHM et al. Efficacy of pre-operative antimicrobial prophylaxis in patients undergoing pancreatoduodenectomy: A multi-center retrospective analysis. Surg Infect (Larchmt). 2018 Aug/Sep;19(6): 608-613

18. Ohashi M, Saka M, Katayama H, Okinaka K, Morita S, Fukagawa T et al. A Prospective cohort study to evaluate the feasibility of intraoperative antimicrobial prophylaxis in open gastrectomy for gastric cancer. Surg Infect, 2015:16(6):833-839.

19. Imamura H, Furukawa H, lijima S, Sugihara S, Tsujinaka T, Tsukuma H,et al. Multicenter phase II study of antimicrobial prophylaxis in low-risk patients undergoing distal gastrectomy for gastric cancer. Gastric Cancer 2006;9: $32-35$ 
20. Imamura H, Kurokawa Y, Tsujinaka T, Inoue K, Kimura Y, lijima S et al. Intraoperative versus extended antimicrobial prophylaxis after gastric cancer surgery: a phase 3, open-label, randomised controlled, noninferiority trial. Lancet Infect Dis 2012;12:381-387.

21. Hirao M, Tsujinaka T, Imamura H, Kurokawa Y, Inoue K, Kimura Y et al; Osaka Gastrointestinal Cancer Chemotherapy Study Group (OGSG). Overweight is a risk factor for surgical site infection following distal gastrectomy for gastric cancer. Gastric Cancer 2013;16:239-244.

22. Utsumi M, Shimizu J, Miyamoto A, Umeshita K, Kobayashi T, Monden M et al. Age as an independent risk factor for surgical site infections in a large gastrointestinal surgery cohort in Japan. J Hosp Infect 2010;75: 183-187.

This work is licensed under a Creative Commons Attribution-NonCommercial 3.0 Unported License which allows users to read, copy, distribute and make derivative works for non-commercial purposes from the material, as long as the author of the original work is cited properly. 